\title{
Dietary Calcium Intake and Associated Factors among Pregnant Women in Southern Benin in 2014
}

\author{
Victoire Damienne Agueh1, Madeleine Flore Tugoué2, Charles Sossa1*, \\ Clémence Métonnou1, Colette Azandjemè1, Noel Moussiliou Paraiso1, \\ Marius-Edgard Ouendo ${ }^{1}$, Laurent T. Ouédraogo ${ }^{1}$, \\ Michel Makoutodé ${ }^{1}$ \\ ${ }^{1}$ Regional Institute of Public Health (IRSP) of Ouidah, Ouidah, Benin \\ ${ }^{2}$ Ministry of Health, Yaoundé, Cameroon \\ Email: vagueh@hotmail.com, mafloflo@yahoo.com, sossajero@yahoo.com, metonnouc@yahoo.fr, \\ eouendo@yahoo.fr, makoutod@gmail.com, laurent tikar@yahoo.fr
}

Received 6 July 2015; accepted 7 August 2015; published 11 August 2015

Copyright (C) 2015 by authors and Scientific Research Publishing Inc.

This work is licensed under the Creative Commons Attribution International License (CC BY). http://creativecommons.org/licenses/by/4.0/

c) (i) Open Access

\section{Abstract}

Hypertensive and its complications during pregnancy are closely linked to maternal mortality and morbidity. Sufficient calcium intake during pregnancy reduces the risk of hypertensive disorders. The objective is to determine dietary calcium intake and associated factors in pregnant women in southern Benin. This cross-sectional study included 176 pregnant women selected by random cluster sampling. Calcium intake was determined from two non-consecutive 24 hours dietary recalls. Demographic and socioeconomic factors were collected from individual interviews. Multivariate logistic regression model was used to identify factors associated with calcium intake controlling for energy intake. The mean daily calcium intake was $561.69 \pm 183.02 \mathrm{mg}$ and the median intake was $560.74 \mathrm{mg}$ per day. The percentage of pregnant women with low calcium intake was $94.60 \%$. The women in the lower economic status tercile $(\mathrm{OR}=0.52095 \%$ CI $0.415-0.653)$ were less likely to have calcium intakes above the median compared to the upper tercile of economic status. Women with secondary or more education level (OR $=1.96195 \%$ CI $1.505-2.555)$ showed a higher odd ratio to have dietary calcium intake above the median value compared to those with no schooling. Low calcium intake was widespread among pregnant women. Calcium supplements and interventions to promote optimal nutrition in pregnant women are needed to protect them from low calcium intake consequences.

*Corresponding author.

How to cite this paper: Agueh, V.D., Tugoué, M.F., Sossa, C., Métonnou, C., Azandjemè, C., Paraiso, N.M., Ouendo, M.-E., Ouédraogo, L.T. and Makoutodé, M. (2015) Dietary Calcium Intake and Associated Factors among Pregnant Women in Southern Benin in 2014. Food and Nutrition Sciences, 6, 945-954. http://dx.doi.org/10.4236/fns.2015.611098 


\section{Keywords}

\section{Calcium, Dietary Intake, Pregnancy, Benin}

\section{Introduction}

Energy and nutrients' needs increase during pregnancy. Particularly, calcium is an essential nutrient for bone health of the mother and fetus. Pre-eclampsia and eclampsia are common causes of serious morbidity and maternal death. Calcium supplementation may reduce the risk of pre-eclampsia, and may help to prevent preterm birth. Sufficient calcium intake reduces hypertension onset and associated disorders during pregnancy [1]-[3]. In developing countries, calcium needs in pregnant women are not always covered and this is a threat to their health and of the fetus [4]-[6].

Gestational hypertension is the second cause of maternal morbidity and mortality worldwide, because it is associated with an increased risk of preterm birth and growth retardation. In Benin, eclampsia is responsible for $12 \%$ of maternal deaths [3]. Supplementation of 300 and $2000 \mathrm{mg} /$ day of calcium during pregnancy in women at high risk for low calcium intake reduces the risk of the occurrence of high blood pressure, pre-eclampsia and premature birth [5] [6].

Dietary calcium intakes in Benin pregnant women are poorly documented. The objective of the study is to determine the intakes of calcium and factors associated among pregnant women in southern Benin in 2014.

\section{Methods}

\subsection{Settings}

The study was carried out in southern part of Benin (Ouidah), 40 kilometers from Cotonou, the economic capital. The population of Ouidah was estimated at 113,026 in 2014 and the expected number of pregnant women in the same year was 5600. Favorable natural conditions exist for agriculture. The annual rainfall amounts are generally sufficient. The economy of the town is characterised by the primary sector characterized by agriculture, fisheries and livestock. Agricultural production is based on maize, cassava, beans, palm oil, coconut, and vegetable [7].

\subsection{Study Design and Subjects}

It was a cross-sectional study which was descriptive and analytical. The study population was women who were pregnant during the investigation period

\subsection{Sample Size}

The size was determined according to the theoretical prevalence of inadequate calcium intakes by $50 \%$ [8] and an accuracy of $10 \%$. The size was multiplied by 1.5 (cluster effect) considering that the subject selected in one neighborhood corresponded to a cluster. By providing $10 \%$ of cases of non-response, a minimum size of 168 participants was required with significance level of $5 \%$ and. Finally, 176 pregnant women were selected.

\subsection{Criteria for Inclusion and Non-Inclusion}

Any pregnant woman who was living in a selected neighborhood or village was eligible for the survey. However, pregnant women with known allergy for dairy products and those who were in poor health and unable to respond to questions were not included in the survey

\subsection{Selection of Subjects}

The sampling method was probabilistic. The sampling technique was random clusters. The number of clusters was proportional to the size of the population in each sampling unit (village/neighborhood). In all selected villages, women were identified randomly. From the center of the village and in a direction chosen at random, all 
houses were numbered. The first house to investigate was chosen randomly. Subsequently the investigator went step by step to reach the expected number of pregnant women. One pregnant woman was chosen by house. If there were more than one pregnant woman in the house, only one was randomly selected.

\subsection{Study Variables}

\subsubsection{Dependent Variables}

The dependent variable was the dietary calcium intake by pregnant women. In order to estimate dietary intake of calcium of the participants, two nonconsecutive 24-hour food recalls [9] [10] has been recorded. For each participant, the 24-hour recalls were recorded with interval of 4 to 5 days, and included one day of the week end. Special days related to a celebration or any party for whom food consumption less corresponded to standard were excluded. Nutrient intake calculations were made using mainly the table composition of West African foods. Food composition table developed in Mali [11] was used for the missing information on other tables. The 24 hours dietary recalls were carried out according to the five steps technique recommended by Conway and Ingwersen [9]. The intake cut off value of $900 \mathrm{mg}$ of calcium a day was considered to define adequate intake for pregnant women [6] [12]. The median value was used to classify pregnant women into two groups: intake below the median and median upper intake.

\subsubsection{Independent Variables}

The independent variables were the socio-economic and demographic factors. The socioeconomic level was a composite variable measured on the basis of several components, namely: ownership of the house where one lives, the possession of land, means of transport, the sources of information, the communication device used, the light source, water supply, the energy source for cooking, soil type and type of toilet in the household. All these item were scored 0, 1 and 2 and the sum of scores determined the socioeconomic level of the household score [13]. Individuals were classified into terciles of socioeconomic level. The education level was the highest level of formal education reached. Data on occupation, household size, number of deliveries and pregnancies, length of the present pregnancy, age, nutrition knowledge and foods whose consumption was prohibited were collected.

\subsection{Data Collection}

Data were collected from 10th April to 15th July 2014 by four trained teams of dieticians and community members.

\subsection{Statistical Analysis}

SPSS Version 20.0 software (SPSS Inc., Chicago, IL) was used for data analysis. Multiple Source Approach Methods (MSM) was used for the adjustment and standardization of intakes of energy and nutrients [14]. Calcium intake was classified to intakes upper or less than the median value. A weighted analysis of the data was done. The proportions and means with their standard deviation were computed. The statistical test of Pearson Chi-square was performed to explore any difference in calcium intake in different economic and demographic sub-groups. Factors associated with calcium intake in the univariate analysis at the p-value less than 0.20 were introduced in a multiple logistic regression model to identify factors associated with calcium intake controlling for energy intake. The significance level for data was $\mathrm{p}<0.05$. The model was adjusted for energy intake

\subsection{Ethical Considerations}

The objectives of the study were explained to participants. Free and informed oral consent was obtained before starting the interview. This consent claims that participants are not at risk by refusing to participate in the survey or stopping their collaboration during the study. The confidentiality and anonymity of the information collected were respected. After the second 24-hour recall nutritional advices were given to pregnant women.

\section{Results}

\subsection{Sociodemographic and Economic Characteristics of Participants}

Average age of women was 25.08 years old ( \pm 5.62$)$. The mean household size was $4.17( \pm 1.7)$ persons. Among 
pregnant women, $69.7 \%$ had reached at least a primary level of education, $37.1 \%$ lived in urban areas and $12.3 \%$ were in the first quarter of pregnancy.

\subsection{Calcium Intakes}

The average intake of calcium was $561.69 \pm 183.02 \mathrm{mg} /$ day and the median intake was $560.74 \mathrm{mg} / \mathrm{day}$. The proportion of pregnant women with low calcium intakes (less than or equal to $900 \mathrm{mg}$ per day) was $94.60 \%$.

Figure 1 describes the usual frequency of consumption of foods rich in calcium. For each food considered, there were at least $50 \%$ of the pregnant women who rarely ate them.

Figure 2 describes the reasons for the non-usual consumption of calcium-rich foods. The most frequent reasons were nausea, preferences, unavailability of food and the unaffordability.

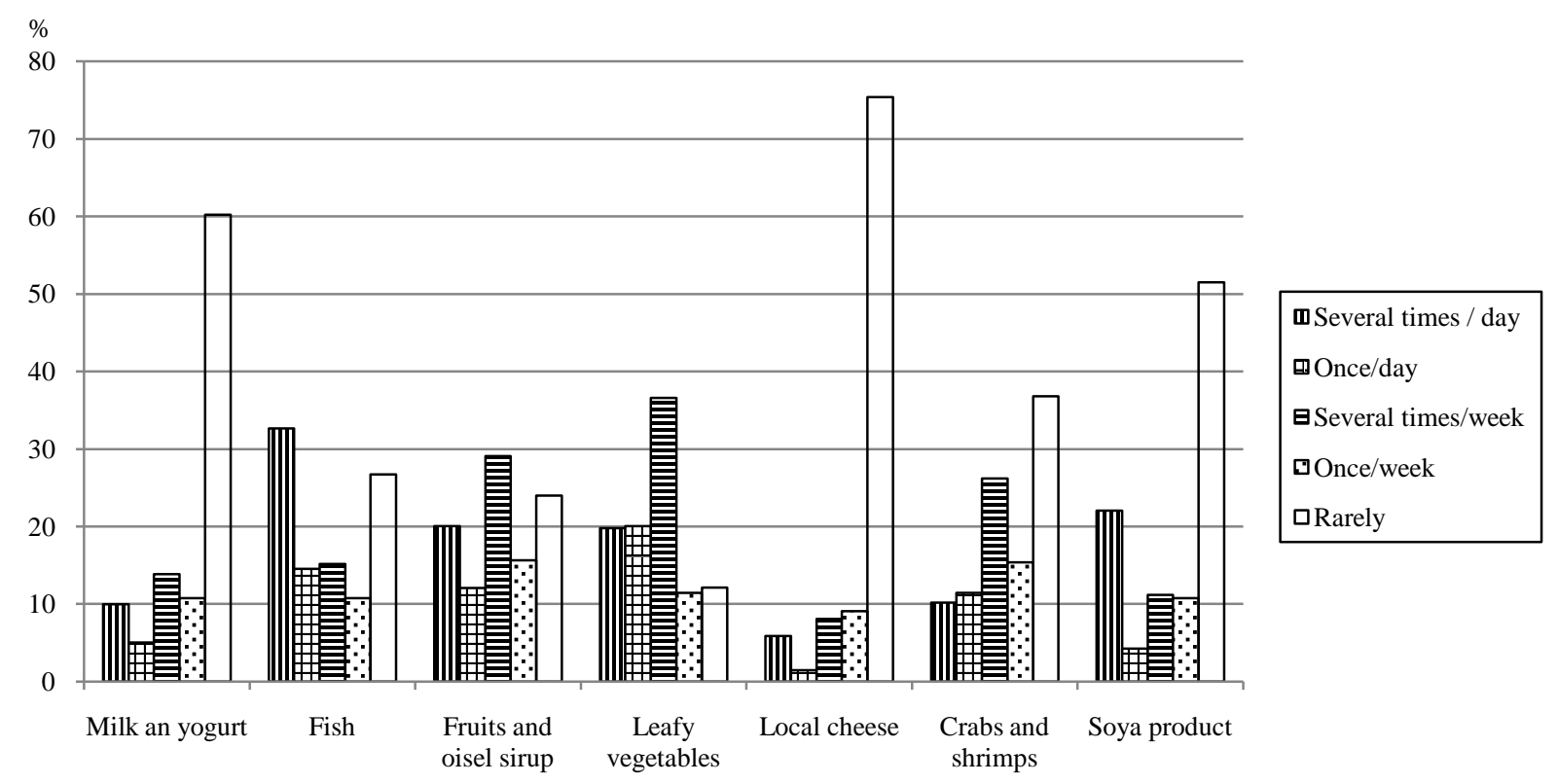

Figure 1. Frequency of calcium-rich food intake.

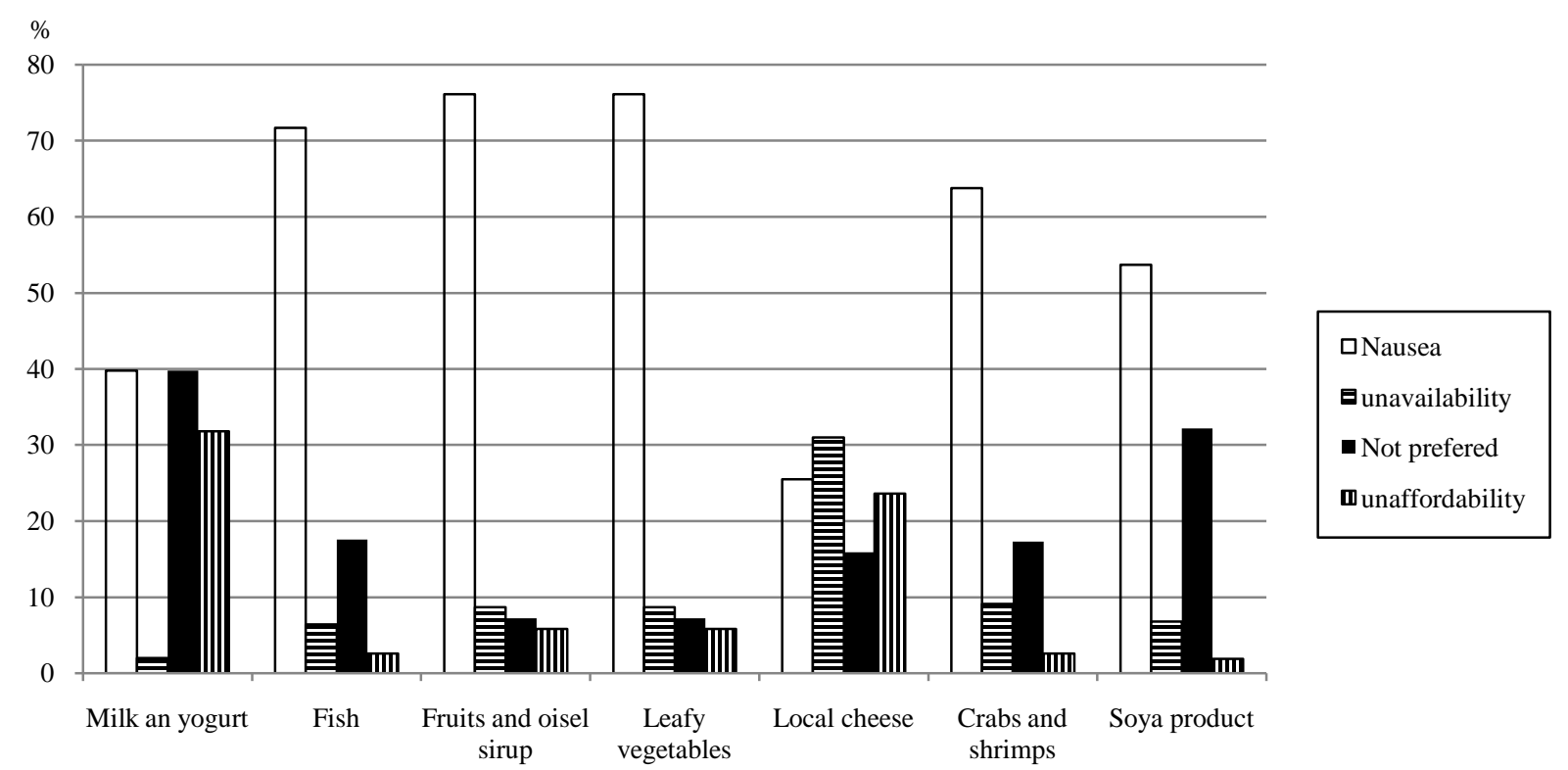

Figure 2. Reasons of non-usual consumption of calcium-rich foods. 


\subsection{Factors Associated with Dietary Calcium Intake}

Table 1 shows the sociodemographic and economic factors associated with dietary calcium intake in univariate analysis. Marital status, level of education, occupation, economic status, place of residence, household size, number of deliveries, and length of pregnancy were the factors associated with dietary intake of calcium. Among nutritional factors, knowledge in nutrition was associated with dietary calcium intake.

In multivariate analysis (Table 2), married women and women with low economic status were significantly less likely to have calcium intakes higher than the median compared respectively to unmarried women and women with higher economic status. Pregnant women in urban areas, women with better knowledge in nutrition and those whose household size is greater than four were significantly more likely to have higher calcium intakes compared to rural women, ones with low nutritional knowledge and those whose households size was four or less, respectively.

\section{Discussion}

The study examined the dietary intake of calcium among pregnant women and associated factors. Low dietary calcium intake was widespread among pregnant women. Dietary calcium intake was associated with economic status, education, nutrition knowledge and place of residence.

\subsection{Dietary Calcium Intake}

The study showed that the average calcium intake in pregnant women in our study was low (561.69 \pm 183.02 mg/day) compared to recommended dietary allowances [15]. This result clearly reflects the low frequency of consumption of calcium-rich products (Figure 1). In agreement with the present results, Phnom Sukchan et al. in Thailand [16] reported mean intake of $523 \pm 168.2 \mathrm{mg} /$ day in 2010. Similarly, low intakes of $400 \mathrm{mg} / \mathrm{day}$ were observed in several communities-based studies in Indonesia by Persson et al. [17] in 2001 and in China by Cheng et al. in 2008 [18]. In contrast, higher dietary calcium intake (1671 \pm 454 mg/day) was observed by Harville et al. in the United States of America in 2009 [19], Erkkola et al. [20] in Finland in 2001 (1710 \pm 654 $\mathrm{mg} /$ day) and Ebrahimi et al. in Iran (968.51 $\pm 363.05 \mathrm{mg} /$ day) [21].

Subsequently to low mean of calcium intake, the prevalence of adequate calcium intake in pregnant women in the present study is very low. Only $5.40 \%$ of pregnant women have adequate calcium intake. This prevalence is similar to those observed by Lindsay et al. [22] among immigrant Nigerian pregnant women in poor areas of Ireland among whom the prevalence of calcium intake was low (7\%). In contrast, higher prevalence of adequate calcium (55\%) was reported by Phnom Sukchan et al. in Thailand in 2010 [16]. Camargo et al. in Brazil reported a proportion of $90 \%$ adequate calcium intake in pregnant women participating in a study on preventing hypertensive disorders by calcium supplementation in 2013 [1].

These different results highlighted differences in dietary patterns. Calcium intake among women in developing countries are generally very low because diets are based mainly on grains and legumes [16] [18] [23], while in developed countries, calcium intake is high due to production and usual consumption of dairy products [19]. Indeed, the frequency of consumption of calcium-rich foods is low in the study population as described in Figure 1.

Knowing that hypertensive disorders and its complications during pregnancy are prevalent in developing countries [4] and the positive role of sufficient calcium intake in reducing the risk of hypertensive disorders, the common inadequate calcium intake during pregnancy in developing countries requires adequate interventions. Two systematic reviews included 21 trials with 19,000 women in developed and developing countries from all continents reported that women who received calcium supplements from the $20^{\text {th }}$ gestational week saw their risk of pre-eclampsia half reduced and risk of high blood pressure reduced by $41 \%$. Similarly, the risk was reduced by $78 \%$ with calcium supplements intervention in women at high risk of hypertension [6]. Supplement of $2 \mathrm{~g}$ of elemental calcium between the $12^{\text {th }}$ and $25^{\text {th }}$ weeks of pregnancy reduced the occurrence of pre-eclampsia and preterm delivery as reported by Kumar et al. [24] in the study that included 524 healthy primigravidas who had a daily calcium intake less than the recommended dietary allowances. Villar et al. [25] observed in the World Health Organization randomized trial of calcium supplementation among low calcium intake pregnant women that a 1.5-g calcium/day supplement did not prevent preeclampsia but did reduce its severity. In a 2015 recent meta-analysis of multicentre randomized controlled trials on calcium supplementation, An et al. confirmed that 
Table 1. Dietary calcium intake and sociodemographic characteristics in pregnant women in southern Benin, 2014 (univariate analysis).

\begin{tabular}{|c|c|c|c|c|c|}
\hline \multirow{3}{*}{ Sociodemographic characteristics } & \multicolumn{4}{|c|}{ Calcium intake } & \multirow{3}{*}{$\mathrm{p}^{* *}$} \\
\hline & \multicolumn{2}{|c|}{$<$ Median value } & \multicolumn{2}{|c|}{$\geq$ Median value } & \\
\hline & $\mathrm{N}$ & $\%^{*}$ & $\mathrm{~N}$ & $\%^{*}$ & \\
\hline \multicolumn{6}{|l|}{ Age } \\
\hline$<25$ years old & 44 & 23.5 & 41 & 23.8 & \multirow{2}{*}{0.385} \\
\hline$\geq 25$ years old & 44 & 27.3 & 47 & 26.1 & \\
\hline \multicolumn{6}{|l|}{ Matrimonial status } \\
\hline Unmarried & 10 & 4.2 & 11 & 6.1 & \multirow{2}{*}{0.001} \\
\hline Married & 78 & 46.6 & 77 & 43.1 & \\
\hline \multicolumn{6}{|l|}{ Education } \\
\hline No schooling & 41 & 20.3 & 32 & 15.1 & \multirow{3}{*}{$<0.001$} \\
\hline Primary school & 31 & 21.6 & 31 & 18.1 & \\
\hline Secondary and high school & 16 & 8.9 & 25 & 15.9 & \\
\hline \multicolumn{6}{|l|}{ Occupation } \\
\hline House wives/students & 24 & 14.8 & 27 & 16.8 & \multirow{3}{*}{$<0.001$} \\
\hline Artisans/employees & 30 & 19.2 & 24 & 12.1 & \\
\hline Resellers/farmers & 34 & 16.1 & 37 & 37.1 & \\
\hline \multicolumn{6}{|l|}{ Economic status } \\
\hline Tercile 1 & 35 & 17.6 & 37 & 16.8 & \multirow{3}{*}{$<0.001$} \\
\hline Tercile 2 & 30 & 16.0 & 24 & 12.0 & \\
\hline Tercile 3 & 23 & 17.2 & 27 & 20.3 & \\
\hline \multicolumn{6}{|l|}{ Length of pregnancy } \\
\hline First quarter & 10 & 6.6 & 11 & 5.7 & \multirow{3}{*}{0.002} \\
\hline Second quarter & 43 & 25.3 & 40 & 21.8 & \\
\hline Third quarter & 35 & 19.0 & 37 & 21.7 & \\
\hline \multicolumn{6}{|l|}{ Number of pregnancy } \\
\hline $1-2$ & 41 & 23.6 & 42 & 23.4 & \multirow{3}{*}{0.910} \\
\hline $3-4$ & 27 & 15.9 & 25 & 15.2 & \\
\hline 5 and over & 20 & 11.1 & 21 & 10.5 & \\
\hline \multicolumn{6}{|l|}{ Number of delivery } \\
\hline $1-2$ & 65 & 37.9 & 65 & 36.1 & \multirow{3}{*}{$<0.001$} \\
\hline $3-4$ & 20 & 11.5 & 18 & 9.9 & \\
\hline 5 and over & 3 & 1.4 & 5 & 3.1 & \\
\hline \multicolumn{6}{|l|}{ Household size } \\
\hline$\leq 4$ & 58 & 34.6 & 55 & 28.6 & \multirow{2}{*}{$<0.001$} \\
\hline$>4$ & 30 & 16.3 & 33 & 20.6 & \\
\hline \multicolumn{6}{|l|}{ Knowledge in nutrition } \\
\hline Adequate & 23 & 15.3 & 23 & 13.2 & \\
\hline Poor & 65 & 35.6 & 65 & 36.0 & 0.033 \\
\hline Nutritional advices received & & & & & \\
\hline Yes & 13 & 7.3 & 21 & 8.7 & \\
\hline No & 75 & 43.5 & 67 & 40.5 & 0.022 \\
\hline Place of residence & & & & & \\
\hline Rural & 47 & 23.0 & 34 & 14.1 & \\
\hline Urban & 41 & 27.8 & 54 & 35.0 & $<0.001$ \\
\hline
\end{tabular}

${ }^{*}$ Weighted percentages; ${ }^{* *}$ Pearson Chi square test. 
Table 2. Dietary calcium intake and associated factors in pregnant women in southern Benin, 2014 (multivariate logistic regression).

\begin{tabular}{|c|c|c|c|}
\hline & \multicolumn{3}{|c|}{ Daily dietary calcium intake $\geq$ median value } \\
\hline & OR & $95 \%$ CI & $\mathrm{p}$ \\
\hline \multicolumn{4}{|l|}{ Matrimonial status } \\
\hline Unmarried & 1 & & \\
\hline Married & 0.566 & $0.414-0.774$ & $<0.001$ \\
\hline \multicolumn{4}{|l|}{ Education } \\
\hline No schooling & 1 & & \\
\hline Primary school & 0.948 & $0.771-1.166$ & 0.614 \\
\hline Secondary and high school & 1.961 & $1.505-2.555$ & $<0.001$ \\
\hline \multicolumn{4}{|l|}{ Knowledge in nutrition } \\
\hline Poor & 1 & & \\
\hline Adequate & 1.489 & $1.221-1.816$ & $<0.001$ \\
\hline \multicolumn{4}{|l|}{ Household size } \\
\hline$\leq 4$ members & 1 & & \\
\hline$>4$ members & 1.330 & $1.092-1.618$ & 0.004 \\
\hline \multicolumn{4}{|l|}{ Economic status } \\
\hline Tercile 3 & 1 & & \\
\hline Tercile 2 & 0.672 & $0.521-0.868$ & 0.002 \\
\hline Tercile 1 & 0.520 & $0.415-0.653$ & $<0.001$ \\
\hline \multicolumn{4}{|l|}{ Length of pregnancy } \\
\hline First quarter & 1 & & \\
\hline Second quarter & 0.880 & $0.676-1.146$ & 0.344 \\
\hline Third quarter & 1.177 & $0.895-1.547$ & 0.243 \\
\hline \multicolumn{4}{|l|}{ Number of deliveries } \\
\hline 5 and over & 1 & & \\
\hline $3-4$ & 0.489 & $0.311-0.771$ & 0.002 \\
\hline $1-2$ & 0.353 & $0.225-0.554$ & $<0.001$ \\
\hline \multicolumn{4}{|l|}{ Nutritional advices received } \\
\hline Yes & 1 & & \\
\hline No & 0.985 & $0.775-1.250$ & 0.898 \\
\hline \multicolumn{4}{|l|}{ Occupation } \\
\hline House wives /students & 1 & & \\
\hline Artisans/employees & 0.655 & $0.512-0.837$ & 0.001 \\
\hline Resellers/farmers & 1.164 & $0.927-1.463$ & 0.191 \\
\hline \multicolumn{4}{|l|}{ Place of residence } \\
\hline Rural & 1 & & \\
\hline Urban & 1.484 & $1.225-1.797$ & $<0.001$ \\
\hline \multicolumn{4}{|l|}{ Energy intake } \\
\hline$<2500 \mathrm{kcal}$ & 1 & & \\
\hline$\geq 2500 \mathrm{kcal}$ & 2.642 & $2.129-3.280$ & $<0.001$ \\
\hline
\end{tabular}


calcium supplementation appeared to reduce the risk of hypertension in pregnancy risk reduction in hypertension in calcium group [26].

Calcium supplements during pregnancy are needed and should be feasible in developing countries where dietary calcium intake is low. The calcium supplement strategy can be implemented like the systematic preventive treatment of malaria and anemia during pregnancy. Further, the sustainable approaches to increase calcium intake in pregnant women in sub-Saharan context should be food diversification.

\subsection{Factors Associated with Calcium Intake in Pregnant Women}

Occupation was associated with adequate calcium. Artisans and employees are less likely to meet adequate need in calcium intake compared with house women and farmers. Artisans and employees should have more financial access to calcium-rich products. But only $50.7 \%$ of women in this occupational category were in the upper tercile of economic status. This showed that the incomes of these women were not substantial to significantly improve their purchasing power and consumption of calcium-rich foods.

The economic status was associated with calcium intake in pregnant women in the present study. Indeed, women belonging to the highest tercile of economic status had a higher average of calcium intake comparing to those in the poorest tercile. This may probably due to financial access to dairy foods which are calcium-rich. Similar results were found by Ebrahimi et al. [21] in Iran in 2012.

The high size of the household and having at least four deliveries increased the likelihood to have adequate calcium intake in pregnant women in the study. This observation can be explained by the fact that these mothers experienced yet the recommended foods to eat during pregnancy following their repeated contacts with midwives. Given also that they have more children, they would often cook meals and eat home prepared meals compared to women in small size households of small size who could purchase already prepared meals with probably poor micronutrient contents [19].

Nausea was found as cause of low consumption of calcium-rich products in pregnant women. This result challenges the health workers to identify techniques to improve consumption of calcium-rich products in pregnant women without complaining for nausea. These techniques may include, for example, how to prepare foods to change the smell and the flavor including consuming small quantities, several times.

Some limitation can be addressed in this study. The technique of 24 hours recall for dietary assessment is associated with recall bias as heavily reliant on memory. Despite this limitation, the study provides useful data on dietary calcium intake in connection with sociodemography and knowledge in nutrition in developing settings.

\section{Conclusion}

The study on calcium intake in pregnant women in Benin in 2014 showed a high prevalence of low dietary calcium intake in this population. Calcium supplements and food diversification during pregnancy through nutrition education are needed to help pregnant women fill calcium requirements to prevent hypertension and associated disorders.

\section{Acknowledgments}

The authors thank participants and field workers in the study.

\section{Conflict of Interests}

The authors declare no competing interests.

\section{References}

[1] Camargo, E.B., Moraes, L.F., Souza, C.M., Akutsu, R., Barreto, J.M., da Silva, E.M., et al. (2013) Survey of Calcium Supplementation to Prevent Preeclampsia: The Gap between Evidence and Practice in Brazil. BMC Pregnancy and Childbirth, 13, 206. http://dx.doi.org/10.1186/1471-2393-13-206

[2] Hacker, A.N., Fung, E.B. and King, J.C. (2012) Role of Calcium during Pregnancy: Maternal and Fetal Needs. Nutrition Reviews, 70, 397-409. http://dx.doi.org/10.1111/j.1753-4887.2012.00491.x

[3] Ministry of Health (2012) National Strategy of Mother, Child and New Born Death Reduction in Benin, Bénin 2012-2015. Cotonou. 
[4] Avendaño-Badillo, D., Hernández-Avila, M., Hernández-Cadena, L., Rueda-Hernández, G., Solano-González, M. and Ibarra, L. (2009) High Dietary Calcium Intake Decreases Bone Mobilization during Pregnancy in Humans. Salud Pública de México, 51, 100-107.

[5] Bhutta, Z.A., Das, J.K., Rizvi, A., Gaffey, M.F., Walker, N., Horton, S., et al. (2013) Evidence-Based Interventions for Improvement of Maternal and Child Nutrition: What Can Be Done and at What Cost? The Lancet, 382, 452-477. http://dx.doi.org/10.1016/S0140-6736(13)60996-4

[6] Palacios, C. and Pena-Rosas, J. (2013) Calcium Supplementation during Pregnancy for Preventing Hypertensive Disorders and their Complications: Reproductive Health Library Comments. World Health Organization, Geneva.

[7] (2006) Decentralization Mission. Ouidah Monograph, Cotonou, 38.

[8] Harville, E.W., Schramm, M., Watt-Morse, M., Chantala, K., Anderson, J.J. and Hertz-Picciotto, I. (2004) Calcium Intake during Pregnancy among White and African-American Pregnant Women in the United States. Journal of the American College of Nutrition, 23, 43-50. http://dx.doi.org/10.1080/07315724.2004.10719341

[9] Conway, J. and Ingwersen, L. (2004) Accuracy of Dietary Recall Using the USDA Five-Step Multiple-Pass Method in Men: An Observational Validation Study. Journal of the American Dietetic Association, 104, 595-603. http://dx.doi.org/10.1016/j.jada.2004.01.007

[10] Persson, V., Winkvist, A., Ninuk, T., Hartini, S., Greiner, T., Hakimi, M., et al. (2001) Variability in Nutrient Intakes among Pregnant Women in Indonesia: Implications for the Design of Epidemiological Studies Using the 24-h Recall Method. Journal of Nutrition, 131, 325-330.

[11] Nordeide, M. (1998) Food Composition Table of Mali. SES Research Project, Environment and Development in Mali, Norway, 42.

[12] Hofmeyr, G.J., Lawrie, T.A., Atallah, A.N., Duley, L. and Torloni, M.R. (2014) Calcium Supplementation during Pregnancy for Preventing Hypertensive Disorders and Related Problems. Cochrane Database of Systematic Reviews, 6, CD001059. http://dx.doi.org/10.1002/14651858.cd001059.pub4

[13] National Institute of Statistics and Economic Analysis (2013) Health and Demographic Survey in Benin (EDSB-IV) 2011-2012. Ministry of Development, Economic Analysis and Forecasting, Cotonou, 402.

[14] Harttig, U., Haubrock, J., Knuppel, S. and Boeing, H. (2011) The MSM Program: Web-Based Statistics Package for Estimating Usual Dietary Intake Using the Multiple Source Method. European Journal of Clinical Nutrition, 65, S87S91. http://dx.doi.org/10.1038/ejcn.2011.92

[15] Andersen, L.T., Thilsted, S.H., Nielsen, B.B. and Rangasamy, S. (2003) Food and Nutrient Intakes among Pregnant Women in Rural Tamil Nadu, South India. Public Health Nutrition, 6, 131-137. http://dx.doi.org/10.1079/phn2002367

[16] Sukchan, P., Liabsuetrakul, T., Chongsuvivatwong, V., Songwathana, P., Sornsrivichai, V. and Kuning, M. (2010) Inadequacy of Nutrients Intake among Pregnant Women in the Deep South of Thailand. BMC Public Health, 10, 572. http://dx.doi.org/10.1186/1471-2458-10-572

[17] Hartini, T.N., Winkvist, A., Lindholm, L., Stenlund, H., Persson, V., Nurdiati, D.S., et al. (2003) Nutrient Intake and Iron Status of Urban Poor and Rural Poor without Access to Rice Fields Are Affected by the Emerging Economic Crisis: The Case of Pregnant Indonesian Women. European Journal of Clinical Nutrition, 57, 654-666. http://dx.doi.org/10.1038/sj.ejcn.1601595

[18] Cheng, Y., Dibley, M.J., Zhang, X., Zeng, L. and Yan, H. (2009) Assessment of Dietary Intake among Pregnant Women in a Rural Area of Western CHINA. BMC Public Health, 9, 222. http://dx.doi.org/10.1186/1471-2458-9-222

[19] Harville, E., Schramm, M., Watt-Morse, M., Chantala, K., Anderson, J. and Hertz-Picciotto, I. (2004) Calcium Intake during Pregnancy among White and African-American Pregnant Women in the United States. The Journal of the American College of Nutrition, 23, 43-50. http://dx.doi.org/10.1080/07315724.2004.10719341

[20] Erkkola, M., Karppinen, M., Javanainen, J., Rasanen, L., Knip, M. and Virtanen, S.M. (2001) Validity and Repro- ducibility of a Food Frequency Questionnaire for Pregnant Finnish Women. American Journal of Epidemiology, 154, 466-476. http://dx.doi.org/10.1093/aje/154.5.466

[21] Ebrahimi, F., Shariff, Z.M., Rezaeian, M., Tabatabaei, S.Z., Mun, C.Y. and Tajik, E. (2013) Socioeconomic Status and Intake of Energy and Sodium Are Associated with Calcium Intake among Pregnant Women in Rafsanjan City, Iran. Journal of Obstetrics and Gynaecology Research, 39, 146-153. http://dx.doi.org/10.1111/j.1447-0756.2012.01948.x

[22] Lindsay, K.L., Gibney, E.R., McNulty, B.A. and McAuliffe, F.M. (2014) Pregnant Immigrant Nigerian Women: An Exploration of Dietary Intakes. Public Health, 128, 647-653. http://dx.doi.org/10.1016/j.puhe.2014.05.001

[23] Mostert, D., Steyn, N.P., Temple, N.J. and Olwagen, R. (2005) Dietary Intake of Pregnant Women and Their Infants in a Poor Black South African Community. Curationis, 28, 12-19. http://dx.doi.org/10.4102/curationis.v28i4.1002

[24] Kumar, A., Devi, S.G., Batra, S., Singh, C. and Shukla, D.K. (2009) Calcium Supplementation for the Prevention of Pre-Eclampsia. International Journal of Gynaecology and Obstetrics, 104, 32-36.

http://dx.doi.org/10.1016/j.ijgo.2008.08.027 
[25] Villar, J., Abdel-Aleem, H., Merialdi, M., Mathai, M., Ali, M.M., Zavaleta, N., et al. (2006) World Health Organization Randomized Trial of Calcium Supplementation among Low Calcium Intake Pregnant Women. American Journal of Obstetrics and Gynecology, 194, 639-649. http://dx.doi.org/10.1016/j.ajog.2006.01.068

[26] An, L.B., Li, W.T., Xie, T.N., Peng, X., Li, B., Xie, S.H., et al. (2015) Calcium Supplementation Reducing the Risk of Hypertensive Disorders of Pregnancy and Related Problems: A Meta-Analysis of Multicentre Randomized Controlled Trials. International Journal of Nursing Practice, 21, 19-31. 